\title{
Correction to: Research on the reform of management system of higher vocational education in China based on personality standard
}

Ying Ling ${ }^{1} \cdot$ Soo Jin Chung ${ }^{2}$ - Liwen Wang ${ }^{1}$

Published online: 7 October 2021

(C) The Author(s) 2021

Correction: Curr Psychol (2021)

https://doi.org/10.1007/s12144-021-01480-6

The article was published with an error on the following:

1. The name of the corresponding author was changed from Su jin Jeong to Soo Jin Chung.

2. Funding Statement should be "The Project Supported by National Social Science Fund of China (Grant No.AJA180008, Grant No. BJA190093) and Wonkwang University in 2021."

The original article has been corrected.

Publisher's Note Springer Nature remains neutral with regard to jurisdictional claims in published maps and institutional affiliations.

The online version of the original article can be found at https://doi.org/ 10.1007/s12144-021-01480-6

Soo Jin Chung

sujinjeong013@gmail.com; sj@wku.ac.kr

1 Zhejiang Industry Polytechnic College, Shaoxing 312000, China

2 Wonkwang University, Iksan-si 54538, South Korea 